\title{
Happiness and other factors behind examination performance of college students
}

Lumontod, Robinson Z., III $\$

Department of Psychology, Central Luzon State University, Philippines (robinsonlumontodiii@ gmail.com)

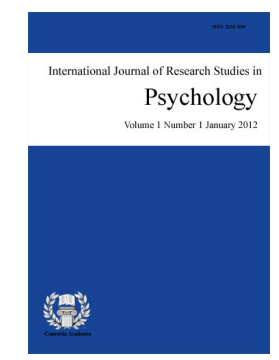

ISSN: 2243-7681 Accepted: 22 October 2018 Online ISSN: 2243-769X

OPEN ACCESS

\section{Abstract}

Studies on happiness had flourished around the world. Different impacts of happiness in different aspects of life had been well documented. In the Philippines however, the study of happiness remained scarce especially in academic setting. In addition, most previous studies focused mainly on GPA as a measure of academic performance. Because happiness is vulnerable to life experiences (Veenhoven, 1997), linking happiness with GPA may not yield a comprehensive and more meaningful result. To fill this gap in the previous inquiries, this study aimed at the less taken angle. Thus, this inquiry focused on the link between happiness and examination outcome of college students. The study was conducted at the Central Luzon State University, Philippines. There were 282 college students participated in the study. Using correlation and test of difference analyses, several findings were noted. Results suggest that happiness had no significant relationship with students' examination performance. Instead, examination performance was associated with the examination's level of difficulty. Happiness on the other hand was correlated with age and gender. Younger students were happier than older ones and female students were happier than their male counterparts. Female students were also found to have longer time spent reviewing the lesson than male students but this difference did not indicate any significant variation in examination score between genders.

Keywords: happiness; examination performance; Filipino college students; academic performance; academic success 


\section{Happiness and other factors behind examination performance of college students}

\section{Introduction}

In recent years, a strand of literature on happiness has been growing posing that happiness is a significant factor in human behavior and performance. But early studies mostly treated happiness as dependent on several predicting variables. Fortunately, recent empirical endeavors turned their lens to the possible influence of happiness on individuals' psychological and physical aspects. Substantial findings suggested its effectiveness in reducing psychological problem such as depression (Omidi, Akbari, \& Mahdian, 2011). In addition, happiness was also found to have a positive impact on health and motivation (Bekhet, Zauszniewski, \& Nakhla, 2008). In fact, early empirical evidence posited that one of the basic components of motivation is happiness (Layard, 2003). These early claims sparked research journeys in the psychological community around the world which aimed to understand both the complexity and relevance of happiness in human lives. Questions sprouted into a wider spectrum of research undertakings from predictors of happiness to its utility in a day to day living. Unlike its early years (when happiness was seen as the dependent variable), recent researches around the world had explored the predictive ability of happiness on multiple dimensions of human activity including academic performance.

To date, studies on happiness and academic performance are numerous around the world but seemingly earned little attention in the Philippines. To fill this gap in the literature, this study was designed to investigate the link between happiness and academic performance of college students. While previous study (Waters, 2011) focused on the impact of happiness on students' academic performance using GPA, this study narrowed its scope on the students' performance on certain examination period and not on the overall academic performance. This paper argued that, if happiness, in its very nature, is tied to life experience and individuals' interpretation of life events (Veenhoven, 1997), then it would be easily affected by life experiences. If so, it may be arguable that happiness is fluid, temporary, changes from time to time, and therefore impossible to cling to its longevity.

GPA, on the other hand, is an accumulated quantity or outcome generated from different academic activities of students during different emotional states. Therefore using GPA as an outcome of happiness might be difficult if not impossible to quantify the link between these two variables if happiness is measured at the single point in time. To possibly determine the link between happiness and academic performance, academic performance must be measured as the result of a single examination period to clearly determine the relationship between these two variables. Drawn from this argument, focusing on the result of single examination period might be crucial to determining the link between happiness and academic performance rather than using grade point average of the students as an indicator of academic performance.

Because today's young students were found to have decreasing interest in school (Yonezawa, Jones, \& Joselowsky, 2009), exploring the link between happiness and academic performance will be of great help to promulgate significant academic intervention to maximize students' potentials in academic activities. Furthermore, school regulations may be revisited and reshaped to permit students' full use of their abilities. Lastly, this study will add to the scarce information on understanding happiness in the Philippine context and its relevance to examination performance.

\section{Review of Related Literature}

\subsection{Happiness and Its Determinants}

Happiness is one's overall perception of his/her life (Veenhoven, 1997) especially the evaluation of one's life's enjoyment (Veenhoven, 2010). Happy people may find life as likable or good, while unhappy ones might 
find life as undesirable. In this instance, the concept of happiness is subjective as it largely depends on individuals' evaluation on current life situation. Veenhoven (1997) further proposed two determinants of happiness. First, life experiences determine happiness. Good life experiences may result in greater happiness while in contrary, bad life experiences may result in unpleasant emotion. Second, the interpretation of life events shapes one's happiness. Because everyone bears unique interpretation on a single instance, numerous and contrasting interpretations may be formed by different individuals. In a modest sense, cognitive response to an event may then affect one's feelings and emotions. Positive interpretation may lead to some degree of happiness, while negative interpretation will induce unhappy feeling.

Previous findings found that happiness could also be influenced by societal changes. As Veenhoven (2010) suggests, the modern way of living makes people of today's generation happier than those who lived in earlier time. The span of time (from hunters and gatherers to industrial era) might not the influential factor on the changes of happiness but the technological advancement that happened within the course of time. The latter claim may be plausible because technologically speaking, the world has become smaller making people closer to each other and day to day chores became lighter and easier. In this sense, happiness seemed to be an outcome of individuals' condition of life. Ultimately, happiness is the result of being calm and be able to retain hope even in miserable situations (Platsidou, 2013). Again, cognitive response plays a significant role in achieving happiness. The question might not be on the nature of the event but on one's cognitive representation of that event.

Along with personal and societal factors, cognitive evaluation of one's ability seemed to pose its predictive ability on happiness. Perception of one's capability to perform a given task may be one of the predictors of happiness. In their study, Pordanjani, Yahyanezhad, and Moharer (2014) found that students' self-efficacy played an important role in being happy. Because the school is a demanding world, believing one's capability to perform and achieve every academic hurdle may result in happy feelings. This claim can be brought into a wider spectrum of life. People with high self-efficacy may be happier than their counterparts and gain more achievements due to their ability to deal with life situations effectively. Questions on currently available literature were not only focused on the prerequisites of happiness but also on the significant outcome of being happy. Thus, some studies investigated happiness and its utility in numerous aspects of human life.

\subsection{The Role of Happiness in Daily Life}

Happiness has become the cornerstone of positive psychology which brought forth the importance of having a positive feeling in the midst of negative event. Positive psychology investigates as to what factors could help the individual to acquire a healthy level of functioning - this is not limited within the individual, but rather on the broader sense of functioning such as in a group or in an organizational level (Gable \& Haidt, 2005). No wonder that happiness studies had gone to different aspects of life. Findings yielded tantalizing claims considering the beneficial impact of happiness in almost all areas of human life. But results in happiness studies were not far from being flawed. In spite of the richness of the studies, findings were considered for some as problematic. The seemingly built-in flaws emanate from the very nature of happiness as a construct being unstable (Brockmann \& Delhey, 2010), the way it is measured (Kalmijin, 2013) and its cultural sensitivity (Ott, 2009). In the Philippines, for instance, happiness is characterized by the absence of sadness, positive feelings, and satisfaction of needs (Datu \& Valdez, 2012). Filipino students in the previous study conceive happiness as a predictor of motivation. They claimed to be motivated when happy. But happiness is more than a predictor of motivation. Similar in other cultural contexts, happiness is a multifaceted concept.

Regardless of the seemingly irreconcilable results, the importance of happiness in human life has found in different studies. For example, Lyubomirsky (2011) found that happiness was associated with not only physical health but also a good social connection, creativity, and productivity. Another study echoed this finding in the academic world. Waters (2011) found a positive impact of happiness in an academic context. The latter study suggests that the application of positive psychology in school yielded significant positive outcome on students' academic success. Such claim verified the main tenet of positive psychology that happy people function well in 
their respective life situations than unhappy ones - and the beneficial contribution of happiness to human life is vast in many dimensions.

The outcomes of happiness were evident on the physical aspect of individuals. Steptoe, Dockray, and Wardle (2009) suggest that happiness was associated with health. Happy individuals may be healthier than unhappy ones. But this finding must not consider happiness as a cure to any health-related problems. At least one evidence argued that happiness could not medicate sickness but rather serves as a preventive measure from becoming sick. Having health problems might not prevent individuals from experiencing happiness but being happy may not grant them freedom from their sickness (Veenhoven, 20008). The ability of happiness to provide good health may be the reason for its relationship with the longer lifespan (Diener \& Chan, 2011). Staying happy throughout lifespan may shield people from having undesirable diseases due to stress, thus provides a healthy and prolonged life. Being happy requires the ability to remain positive even in undesirable situations could make individuals respond to stress positively (Naseem \& Khalid, 2010). In the academic context, school is a demanding world that often causes stress on students. Thus, happiness may be both helpful and influential factors that could mold students' academic performance.

\subsection{Happiness and other factors of Academic Performance}

Previous studies on students' academic performance were multi-layered. Primarily, the focus of those studies was on factors behind students' school engagement; what makes them stay, what makes them drop from school. The engagement was found to be one of the influential factors in academic achievement (Baron-Lopez \& Vega-Cuesta, 2013). Engagement, however, is not the center of academic success but the part of it. Like other constructs, academic performance was believed to be complicated and could easily be affected by a number of internal attributes of a person (Jimerson, Compos, \& Greif, 2003) and could be different from one student to another. Therefore, there may be no single explanation that could be considered concrete for all students' academic success (Barea, Tsvetovat, Daun-Barnett, \& Greenwald, 2015). In other words, every student may be motivated by various things. This may be due to diverging internal and external factors that might affect students' educational pursuit. For example, Xiao, Tang, and Shim (2009) suggest that familial financial capability contributes to students' academic performance. Better family financial status might have a significant contribution to better academic performance.

Familial financial instability may indirectly cause students to get disengaged with school activities. This is not due to discouragements as a result of financial tightness, but because of the students' sense of obligation to help their parents to earn money. At least one study had argued that some students in Latin America were found to have decreasing academic performance due primarily to the sense of obligation to help their parents doing their livelihood (Telzer \& Fuligni, 2009). Decreased academic performance can be attributed to having lesser school participation (Jennings, 2003). Otherwise, when students feel satisfied with their lives they tend to succeed academically (Rode et al., 2005). On the other hand, some believed that social relation and self-discipline may have played an important role in students' academic success. Furrer and Skinner (2003) argued that children's sense of being involved with others is an important predictor of academic performance. While Duckworth and Seligman (2005) suggest that academic failure is the primary result of having a lack of self-discipline. Another study supports the latter finding. Macan, Shahani, Dipboye, and Phillips (1990) suggest that being unorganized contributed to students' low academic performance.

Self-efficacy was also considered as one of the predictors of students' academic performance (Zimmerman, 2000; Fenollar, Roman, \& Cuesta, 2007). Along with self-efficacy, individuals' personality especially conscientiousness, was found to be a significant predictor of academic achievement (Lievens, Coetsier, De Fruyt, $\&$ De Maeseneer, 2002). Furthermore, academic performance seemed to be predicted by societal factors. More than personal attributes, Wenglinsky (2002) found that school teachers may have played an important role in students' academic achievement. Better teaching strategy may contribute to high academic achievements on students. However, the relationship between happiness and students' academic performance was diverging. The 
role of happiness in academic performance could not be held ubiquitous. For example, Tabbodi, Rahgozar, and Abadi (2015) suggest that happiness had a significant relationship with students' academic achievement. But Tuntiwarodom and Potipiti (2008) found no significant link between happiness and academic performance of students. If happiness is a concept that is susceptible to life experiences (Veenhoven, 1997) and unstable (Brockmann \& Delhey, 2010), exploring its predictive ability on academic performance may be inappropriate because the academic performance is mostly measured by grade point average of the students. Bearing this into consideration, it might be important that the two variables are measured simultaneously at a given period of time to capture the real association between happiness and academic performance using examination score.

\subsection{Current Study}

Based from the above argument, this study sought to understand happiness in the Philippine context and its possible link with academic performance using single examination score of college students in one of the largest public universities in the country. Demographic characteristics of students and their relationship with happiness were also considered. Gender differences in both happiness and examination score were determined.

\section{Method}

\subsection{Design}

This study employed a correlational design in assessing college students' happiness and its relationship with examination performance. Students' happiness was assessed using the Oxford Happiness Questionnaire (OHQ) (Hills \& Argyle, 2002) with the reliability of $\alpha=0.91$. It has 6-point response scale $(1=$ Strongly Disagree, $6=$ Strongly Agree). OHQ was used due to two main reasons. First, the scale is widely used worldwide. For example, Pordanjani, Yahyanezhad, and Moharer (2014), and Tabbodi, Rahgozar, and Abadi (2015) used OHQ in their studies on happiness and academic achievement in Iran. Second, OHQ was dominantly used on college students. Since the participants in this study were college students, using OHQ was found to be appropriate.

The overall questionnaire of this study was divided into three parts. The first part assessed the students' demographic characteristics such as age, weekly allowance, parents' educational attainment, and the length of time they spent studying their lesson. The second part was the assessment of the examination's level of difficulty using the self-constructed question: What do you think the level of difficulty of the exam you have just taken? Students responded to this question using a 4-point scale ( 1 = Very Hard, 4 = Very Easy). The third part was the Oxford Happiness Questionnaire.

\subsection{Participants}

There were 282 college students enrolled in the introduction to psychology course from different colleges of Central Luzon State University, in the Philippines, participated in this study. Participants' age ranging from 16-32 $(M=16.60, S D=1.53)$. The actual data gathering was during the first term examination of the course during the first semester of A.Y. 2017-2018. Participants were purposively selected. Before the students started the examination, the researcher distributed the OHQ scale and had the students responded to the scale. After students were through with the scale, examination questionnaires were distributed. Right after the examination, the students were told to evaluate the level of difficulty of the exam. The students then responded to the single question on the second part of the questionnaire. This procedure allowed the researcher to determine students' perception on the difficulty of the exam.

\subsection{Ethical Considerations}

Prior to the actual data gathering, the participants were informed about the nature of the study and their right to withdraw from the study anytime if they want to without any obligation. They were also informed that their 
Lumontod, R. Z., III.

participation was mainly voluntary and they were not obliged to do so. The confidentiality of the result was assured as well as the anonymity of the participants if ever the study will be published.

\subsection{Data Analysis}

In testing the association for happiness with examination score, age, and the weekly allowance, the Pearson $r$ correlation was used. While the relationship between happiness and parental educational attainment, the Spearman Rho correlation was employed. Similarly, the correlation for examination score with time spent in reviewing the lesson and examination level of difficulty were also analyzed with the Spearman Rho. Lastly, the difference between sexes in terms of happiness, examination score and the length of time spent in reviewing the lesson, was tested using Independent Samples T-test.

\section{Results}

This study was primarily guided by several objectives. The first one was to explore the relationship between happiness and examination scores. Second, to determine the relationship for happiness with examination score, age, weekly allowance, and parents' educational attainment. Third, to explore the relationship for examination score with the estimated time spent in reviewing the lesson and the level of difficulty of the exam. Lastly, to determine the difference between sexes in terms of students' happiness, examination score and the length of time spent reviewing the lesson.

\section{Table 1}

Happiness and Exam Difficulty Level

\begin{tabular}{lccc}
\hline \multicolumn{1}{c}{ Factors } & Mean Score & $S D$ & Description \\
\hline Happiness & 4.23 & .46 & Pretty Happy \\
Exam Difficulty Level & 2.04 & .47 & Hard \\
\hline Note. $N=282$ for all analyses. & & &
\end{tabular}

The overall score of student participants on the OHQ was high $(M=4.23 ; S D=.46)$ which means that the students were pretty happy. In addition, students assessed the difficulty level of the given exam as hard $(M=$ $2.04 ; S D=.47)$.

Table 2

Pearson Moment Correlations for Happiness with Exam Score and Demographic Characteristics

\begin{tabular}{lccc}
\hline \multirow{2}{*}{ Factor } & \multirow{2}{*}{ Exam Score } & \multicolumn{2}{c}{ Demographic Characteristics } \\
\cline { 3 - 4 } & & Age & Weekly Allowance \\
\hline Oxford Happiness Questionnaire & 0.03 & -.110 & -.003 \\
\hline Note. $N=282$ for all analyses. & &
\end{tabular}

Note. $N=282$ for all analyses.

The Pearson Moment correlation analysis found no significant relationship between happiness and examination performance of the students $(r=.03 ; p=.62)$. Similarly, age $(r=-.11 ; p=.07)$ and weekly allowance $(r=-.003 ; p=.959)$ were found to have no significant correlation with happiness.

Table 3

Spearman Rho Correlation for Happiness and Parents' Educational Attainment

\begin{tabular}{lc}
\hline & Parents' Educational Attainment \\
\hline Oxford Happiness Questionnaire & .010 \\
\hline Note. $N=282$. &
\end{tabular}

In addition, using the Spearman Rho correlation analysis, parents' educational attainment was found to have no significant relationship with students' happiness $\left(r_{s}=.010 ; p=.821\right)$. 
Happiness and other factors behind examination performance of college students

Table 4

Spearman Rho Correlation for Exam Score with Time Spent Reviewing the Lesson and Exam Level of Difficulty

\begin{tabular}{lcc}
\hline \multicolumn{2}{c}{ Time Spent Reviewing the Lesson } & Exam Level of Difficulty \\
\hline Exam Score & .002 & $.133^{* *}$ \\
\hline Note. ${ }^{* *}=p<.01 . N=282$ for all analyses.
\end{tabular}

However, the level of difficulty of the examination was found to have a weak significant relationship with the examination score $(r=.133 ; p=.006)$. The time spent in reviewing the lesson prior to examination had no significant link with examination performance $\left(r_{s}=.002 ; p=.959\right)$.

Table 5

Happiness, Exam Score and Time Spent Reviewing the Subject Means for Males and Females

\begin{tabular}{|c|c|c|c|c|}
\hline & \multicolumn{2}{|c|}{ Gender } & \multirow{2}{*}{$t$} & \multirow{2}{*}{$d f$} \\
\hline & Females & Males & & \\
\hline \multirow[t]{2}{*}{ Happiness } & 4.28 & 4.16 & $-2.27^{*}$ & 280 \\
\hline & 0.4 & 0.51 & & \\
\hline \multirow[t]{2}{*}{ Exam Score } & 44.47 & 43.25 & -1.24 & 280 \\
\hline & 7.54 & 8.84 & & \\
\hline \multirow[t]{2}{*}{ Time Spent Reviewing the Subject } & 2.2 & 1.8 & $-2.88 * *$ & 280 \\
\hline & 1.22 & 1.07 & & \\
\hline
\end{tabular}

Note. $*=p<.05, * *=p<.01 . N=282$ for all analyses.

Differences in happiness and examination score between sexes ware tested using independent $\mathrm{T}-$ test. Results show that females had higher happiness score $(M=4.28, S D=.40)$ than males $(M=4.15, S D=.51)$. The observed difference in happiness score was significant $(t(280)=-2.265, p=.024)$. The examination score between male $(M=43.25, S D=8.84)$ and female students $(M=44.47, S D=7.54)$ was not insignificantly different $(t(280)=-1.243, p=.215)$. Lastly, the difference in the length of time spent in reviewing the lesson between male $(M=1.81, S D=1.07)$ and female $(M=2.21, S D=1.22)$ students was significant $(t(280)=-2.881$, $p=.004)$.

\section{Discussion}

This section discusses and explains the possible implications of the current findings. The analyses showed that happiness failed to establish its link with college students' examination performance. Instead, examination outcome seemed to be related to the level of difficulty of the exam not on the length of time spent in reviewing the lesson, age, weekly allowance and parental educational attainment. In addition, the moderate significant difference between sexes was noted in terms of students' happiness. Females were happier than male students. Lastly, the difference was also found between sexes in time spent reviewing the lesson. Discussions and implications of the findings are further discussed below.

\subsection{Happiness and Examination Performance}

The descriptive analysis shows that the students had a high level of happiness. But correlational analysis indicated no significant link between happiness and examination score. The failure to establish the relationship between happiness and examination performance may have several implications. First, although some studies tied happiness with academic performance (Tabbodi, Rahgozar, Mozaffari, \& Abadi, 2015; Zulkifti, 2013) it is hard to pave clear-cut definitive conclusion. The uncertainty may emanate from the fact that academic performance alone is a complex dependent construct of numerous influential factors such as life satisfaction (Rode et al., 2005), personality (Lievens, Coetsier, De Fruyt, \& De Maeseneer, 2002), school engagement (Casuso-Holgado et al., 2013), sense of relatedness (Furrer \& Skinner, 2003), and self-discipline (Duckworth \& Seligman, 2005). In other words, academic performance is multifaceted that is there would be no single variable can be held constant and definite for all students' academic achievement (Berea, Tsvetovat, Daun-Barnett, \& 
Greenwald, 2005). It would be possible that any relationship observed between happiness and academic performance is an outcome influenced by several latent processes and not merely by happiness.

Second, although happiness is an important component of human motivation (Layard, 2003; Bekhet, Zauszniewski, \& Nakhla, 2008), it does not guarantee success to all happy people on whatever they do. It is worthy to ponder that success may not be dependent on emotional dimension such as happiness while performing a task at hand but on what motivates an individual to pursue something. Built on this assumption, happiness may not be the direct influential factor on performance but motivation. In the context of this study, being happy may not result in better academic performance - it would be a question of whether or not students were motivated or prioritized their school activities. This study suspects that motivation and priority drive academic success not happiness though happiness might have caused the sequential effect.

In the Philippine context, the study of Datu and Valdez (2012) found that happiness fuels Filipino adolescents in pursuing their goal. Happiness also gives strength and focus to Filipino students. However, the previous study was rather too general. The students did not mention what goal they pursued. Therefore, assuming that happiness is an instrumental factor on educational success might be inappropriate. In this study, the Filipino adolescent participants also found to have a high level of happiness. However, such degree of positive feeling did not indicate a significant link with the exam score. The reason maybe is that adolescents' happiness could be related to their external activities but not with the academic performance. This observation stemmed from the conclusion of Yonezawa, Jones, and Joselowsky (2009). The latter study suggests that adolescents today may have lost interest in school activities. In other words, college students participated in this study may have different priorities in their lives bigger than academic aspiration. This observation may lead to an assumption that school activities, as suggested by Yonezawa, Jones, and Joselowsky, may have nothing to do with students' happiness.

The modern world boosts happiness as Veenhoven (2010) argued. Unfortunately, students seem to ignore academic importance leaving school activities less prioritized. The plausible explanation could be that happiness and academic performance are two different and unconnected constructs. Being happy, as seen among the participants of this study, may not necessarily result in higher examination score. There may be several things that made students happy or were they motivated by external factors not an academic endeavor. This may strengthen the argument that happiness may have no direct influence on examination performance. This assumption, however, is beyond the context of the current investigation. Nonetheless, this study accords with the previous finding of Tuntiwarodom and Potipiti (2008) which suggests that happiness and academic performance had no significant relationship.

Third, the problem encountered in studying happiness resides in its very nature. As Veenhoven (2006) suggests, happiness has two dimensions, the overall and the component happiness. The overall happiness is the global assessment of one's enjoyment in life. While component happiness is a momentary feeling of joy as a response to everyday experiences. The problem is, as Veenhoven argued, people might have sometimes, if not most of the time mistaken as to what kind of happiness they consider when formulating their response when they were asked how happy they are. This tendency is likely to occur because sometimes it would be hard to determine what type of happiness surfaces at a given time. This conceptual issue might have affected the result of this study. The students participated in this investigation had given their responses but not certain what type of happiness being asked. They may have mistakenly interpreted the questions on happiness scale resulted in inaccurate responses. Therefore any interpretation should be with a caveat. The insignificant link between happiness and examination performance found in this study may be the result of the fluidity of the construct being measured.

It is important to note that academic performance in this study was not the GPA of the participants. Rather, academic performance was measured using the students' actual score from the given examination. The reason behind choosing the examination score over the GPA was the assumption that happiness can be easily affected 
Happiness and other factors behind examination performance of college students

by daily experience (Veenhoven, 1997). Thus, to capture the true link between happiness and academic performance, examination score was used. Measuring academic performance using the actual exam score can be more appropriate to capture the true relationship between these two variables. However, examination outcome was found to be correlated with the level of difficulty of the examination alone, not with time spent in preparation. As much as happiness, examination performance is multifaceted. The outcome of the exam may be dependent on the construction of the test items. The easier the exam, the higher the outcome may be. Therefore, examination performance may be the direct impact of how teachers/instructors consider students' capability. Built on this result, it may appropriate to perceive examination outcome as the function of the complexity of the exam. This assumption is supported by the previous study. For example, Wenglinsky (2002) argued that teachers play a significant role in students' academic success. Regardless of the preparation, students may find it hard when questions during the examination were deliberately constructed in a way that can induce hardship during the examination. Thus, grades may or may not be a good indicator of students' overall cognitive ability.

In addition, self-efficacy might play an important role in an examination outcome (Fenollar, Roman, \& Cuestas, 2009). Findings were evident that self-efficacy or one's belief in his/her capability to succeed on the task at hand was among of the multi-layered factors on individuals' success. The finding might further suggest that believing in one's ability outdoes preparation of the task. But this suggestion must not undermine the importance of preparation prior to the task. After all, academic success may be determined by self-discipline. Lack of this personal attribute may have a direct impact on academic performance. The finding of Duckworth and Seligman (2005) supports the latter argument. The previous study highlighted the fact that failure in academics was caused by being neglectful of priorities and having no self-discipline.

\subsection{The Role of Time Spent in Reviewing the Lesson and Examination Difficulty Level on Examination Score}

The Spearman correlation analyses suggest that the time spent in reviewing the lesson was not significantly correlated with the exam score but the exam difficulty level. This may suggest that the length of time that students review their lesson does not predict the examination outcome. The exam score, as indicated in the analysis, is the outcome of the exam difficulty level. This study corroborates and contrasts previous findings.

In one study, Barbarick and Ippolito (2003) found that the time students spent reviewing their lesson predict exam score. But in the present study, the result seemed to provide another route in terms of understanding students' exam performance. This may only suggest the existence of numerous latent factors which the current investigation did not take. The inability of a single research endeavor to answer all possible questions concerning academic performance may yield a valid assumption but not a concrete fact. Other findings may bear another argument and scientific evidence. For instance, the findings of Foster, Guo, and Xu (n.d.) argued that the time students' spent reviewing their lesson was negatively related to examination score. The authors further argued that the observed inverse relationship was primarily due to students' internal attributes. Students who are less able to perform academic demands tend to spend more time in reviewing the lesson but do not necessarily have high examination score.

Taking individual's internal attributes to explain students' examination score seemed to be the possible explanation as to why the findings in this area vary. Previous studies also found that intelligence and other physical factors of students may have also played a significant role in examination performance (Rasul \& Bukhsh, 2011; Ukpong \& George, 2013). The difficulty level of the test questionnaire, as found in this study, was moderately correlated with the students' examination score. The current result supports the previous findings. At least one study suggests that the difficulty level of items in the questionnaire largely affects the outcome of the examination result (Ahmad, Marzouqi, \& Hussien, 2014). While the ordering of questions does not predict the examination score (Sue, 2009).

This current finding suggests that the manner how teachers or educators design their examination instruments could largely influence the students' test outcome. In this sense, the examination score or the 
academic performance of students, in general, is largely determined by the teacher's decision. Thus, the academic performance may not be a good assessment of how much does a student learn, or how smart a student is. Instead, academic performance can be reasonably viewed as a multicomponent construct that bears no single explanation.

\subsection{Demographic Variables and Happiness}

Both age and weekly allowance were not associated with happiness. The current finding contrasts several studies which found age and financial status as influential factors on happiness. First, the finding of Omidi, Akbariand, and Mahdian (2011) for example suggests the association between age and happiness. But it is not the case in the present investigation. The contrasting result may be due to the cultural implication. In the Philippine context, happiness is usually perceived as the outcome of external rather than internal factors. Studies conducted in the Philippines found the predictors of happiness among Filipino adolescents. For instance, Primasari and Yuniarti (2012) identified three important factors of happiness among Filipino teenagers. Those factors include social relationship, personal achievement, and religiosity. Adolescents in the previous study consider their family as the strongest predictor of their happiness. In addition, social belongingness also played an important role in the attainment of happiness. Adolescents who have better familial and social relationships were happier than their counterparts who had poorer social connections. This could also be accounted for the observed level of happiness among adolescents who were engaged in farming in the Philippines (Tolentino \& Dullas, 2015). Filipino adolescents who work in the farm were found to have a high level of subjective well-being despite the challenging and hard nature of their job. Whether the observed consistent level of happiness in several studies in the Philippines reflects the innate nature of Filipinos is still the subject that worth a future investigation.

Secondly, the current finding contradicts the study of Shelef, Zdaka, and Barak (2015) which suggests that family income was associated with happiness. Although this inquiry did not directly measure participants' parents' income, it was assumed that students' weekly allowance may somehow reflect the family income. Taken the result into consideration, it may be reasonable to perceive that money is not the only influential factor of happiness. In the Philippines, as discussed above, social interaction plays important role in attaining happiness. Filipino adolescents value interpersonal relationships over other things. Thus, having the better social connection made them happy. This observation can also be found in other cultural contexts. The same result was found in Bangladesh (Devine, Hinks, \& Naveed, 2017). Social interaction plays an important role in happiness. Such social connectedness was embedded in the context of religion. People with the same religious practices stay together and happier than their counterparts. In the Philippines however, the social fabric among Filipinos is not solely the outcome of religion itself but also the valuing of others' upbringing. This is best described as Kapwa, (Enriquez, 1977) a Filipino concept of social connectedness. It is a cultural norm of valuing others. The Kapwa serves as a social glue that creates strong and smooth social interaction. The level of happiness found in this study could be the result of better social connectedness. Filipinos who have a larger group of friends and significant others are usually happier.

\subsection{Gender Difference on Happiness and Examination Outcome}

Female students were happier than male students. Gender difference in happiness was significant - female students were happier than male students. The result accords with the findings of Bojanowska and Zalewska (2015) which suggests that women were happier than men. Factors of happiness among women were more complicated than female college students. It involved several external factors such as socio-demographic status and social interaction. Similar finding (Zang \& Man Tsang, 2013) suggests that income was one of the influential factors on the happiness of women but this effect was dictated by commitment in a marital relationship. Although earned slight similarity, the current finding found no deeper interpretation on the finding due to the fact that previous studies held samples from women and not from a younger population such as college students. Several latent factors must have been affecting students' happiness such as cultural and social forces. For 
Happiness and other factors behind examination performance of college students

example, happiness was found to be related to geographic location (Snoep, 2008). At a macro level, happiness was also related to governmental management (Ott, 2011). But again, this assumption is rather too general to interpret the current finding. However, the current finding contrasts with one previous study in the Philippines. Perez (2012) found no significant difference between males and females in terms of their level of emotional states. This includes both positive and negative affect. The possible explanations for this inconsistent result might be the fact that happiness is susceptible to countless causing factors. Income and the geographical locations, for instance, may have influenced the variability of the result.

On the other hand, examination outcome did not significantly vary between sexes. However, the results showed a significant difference between male and female students in their time spent reviewing the lesson. This finding contradicts with several previous studies. At least five studies found that female outperformed male students. Differences in academic performance were noted (Pomerantz, Altermatt, \& Saxon, 2002) most of the female students yielded higher academic performance than males. The difference was associated with different factors. For example, Sheard (2009) suggests that commitment was a predictor of academic performance of female students. Another explanation was that, female academic performance was due to employment demand of females, in turn, this made female students tend to exert more academic effort than male students (Castagnetti \& Rosti, 2007).

Taken together, the current finding may suggest contrast possibility. Differences among findings in academic performance between genders might be the outcome of social and cultural forces. It is worthy to note that previous studies were conducted in a different geographical location making it difficult if not impossible to make comparison due to uncontrolled external factors. Both social and cultural tendencies of each country differ in many dimensions, thus complicate generalizability.

The present study, on the other hand, may bear unique findings. A significant difference was noted between sexes in terms of time spent reviewing the lesson. Female students had a higher amount of time spent in preparation for the examination than their male counterparts. Therefore, female students might be more active and motivated in doing scholastic tasks than male students. This finding supports the latter study of Duckworth and Seligman (2006). Both authors suggest that academic performance was predicted by self-discipline. Self-discipline made girls higher in academic performance than boys regardless of intellectual capacity. Female students were more disciplined than males. This difference in self-discipline predicts academic performance. But the amount of effort found among female students in this study did not make them higher than males in the examination outcome. This may suggest that other factors might contribute to the academic performance of the students. Effort alone may not be enough to gain academic excellence. In addition, if examination score was almost perfectly the same between sexes, another assumption may be possible. Male students seemed to be more capable of achieving academic performance equal to females without spending the same amount of scholastic effort as females did. Although not directly tested in this study, intellectual capability and other latent factors may have played their role on academic performance. For example, Hackett, Betz, Casas, and Rocha-Singh (1992) emphasized the importance of individuals' evaluation on their capacity to achieve at a given task and people's support contribute to academic performance. Do males have higher self-efficacy than females? This question is beyond the scope of the present study but worthy of future exploration.

In sum, both happiness and academic performance are equally complex and multidimensional. Nonetheless, the findings somehow contribute significant yet modest new understanding of the link between happiness and daily life activities. Academic performance in the context of this study was found to have no significant link with happiness but only the level of difficulty of the exam. This finding contradicts, but to some extent, accords with previous studies. Interpreting the result may involve consideration of external factors (e.g. social and cultural). Female students were happier than males. While there was no significant difference noted between sexes in the examination score.

Aside from understanding the role of happiness in college students' examination score, this study bears at 
least one important implication. Although the noted relationship between examination score and examination level of difficulty was weak, it may be ample to argue that the fate of students in a single examination period in particular or in their overall academic performance in general, lies on the teacher's hands. The best practice for teachers may be, is to give students fair treatment. Teachers should remain objective and fair in giving an assessment to their students. The examination is meant to test how much students learned in the class, not as a form of punishment. Lastly, teachers should consider the innate strengths and weaknesses of the students.

Although the findings of this study were significant in understanding the possible outcome of happiness on students' academic performance specifically of college students, several limitations must be considered. First, respondents were not randomly selected. Second, the correlational study could only describe the relationship between variables but not predictability. Lastly, the instrument used was the standardized scale of happiness which, in the assumption of this study, might have led some difficulty to the respondents in responding to every item due to the language being used. As a result, responses may not be accurate. Using a translated measure of happiness into the local language in the future studies may be more appropriate to capture more reliable data. Further, more comprehensive analyses may also be important to have a better understanding of the nature and impact of happiness on examination score in particular and on academic performance in general.

\section{Conclusion}

This study explored the link between happiness and examination score among Filipino college students. Findings suggest that the participants had a higher level of happiness. However, such degree of happiness had no significant relationship with examination performance of the students. Instead, examination performance was associated with the examination level of difficulty. Furthermore, the gender difference in happiness was found. Female students were happier than male. Female students were also found to have longer time spent reviewing the lesson than male students. Although female students spent more time reviewing the subject, examination score did not differ between sexes. Some factors might have influenced the examination score of the students that beyond the scope of this study.

Acknowledgment: This research was approved by the Ethics Review Board. The author wants to thank Angelo R. Dullas, Maria Rosario I. Bulanan, and Karen DG. Alvarez as members of the review board for their impartial critique and guidance. And most importantly, for approving this endeavor upon considering the implementing rules on research ethics.

\section{References}

Ahmad, M. A., Marzouqi, A., \& Hussien, M. (2014). Exit exam as academic performance indicator. The Turkish Online Journal of Educational Technology, 13(3), 58-67.

Barbarick, K. A., \& Ippolito, J. A. (2003). Does the number of hours studied affect exam performance? Journal of Natural Resources and Life Sciences Education, 32, 32-35.

Bekhet, A. K., Zauszniewski, J. A., \& Nakhla, W. E. (2008). Happiness: Theoretical and empirical considerations. Nursing Forum, 43(1), 12-23. https://doi.org/10.1111/j.1744-6198.2008.00091.x

Berea, A., Tsvetovat, M., Daun-Barnett, N., Greenwald, M., \& Cox, A. (2015). A new multi-dimensional conceptualization of individual achievement in college. Decision Analysis, 2(3). https://doi.org/10.1186/s40165-015-0012-8

Bojanowska, A., \& Zalewska, A. (2015). Lay understanding of happiness and the experience of well-being: Are some conceptions of happiness more beneficial than others? Journal of Happiness Studies, 17(2), 793-815. https://doi.org/10.1007/s10902-015-9620-1

Brockmann, H., \& Delhey, J. (2010). Introduction: The dynamics of happiness and the dynamics of happiness research. Social Indicator Research, 97, 1-5. https://doi.org/10.1007/s11205-009-9561-3

Castagnetti, C., \& Rosti, L. (2007). Effort allocation in tournaments: The effect of gender on academic 
Happiness and other factors behind examination performance of college students

performance in Italian Universities. Munich Personal RePEc Archive. Retrieved from http://mpra.ub.uni-muenchen.de/26194/

Casuso-Holgado, M. J., Cuesta-Vargas, A., Moreno-Morales, N., Labajos-Manzanares, M. T., Baron-Lopez, F. J., \& Vega-Cuesta, M. (2013). The association between academic engagement and achievement in health sciences students. BMC Medical Education, 13(33). https://doi.org/10.1186/1472-6920-13-33

Datu, J. A., \& Valdez, J. P. (2012). Exploring Filipino adolescents' conception of happiness. International Journal of Research Studies in Psychology, 1(3), 21-29. https://doi.org/10.5861/ijrsp.2012.251

Devine, J., Hinks, T., \& Naveed, A. (2017). Happiness in Bangladesh: The role of religion and connectedness. Journal of Happiness Studies. Retrieved from https://doi.org/10.1007/s10902-017-9939-x

Diener, E., \& Chan, M. M. (2011). Happy people live longer: Subjective well-being contributes to health and longevity. Applied Psychology: Health and Well-being, 3(1), 1-43. https://doi.org/10.1111/j.1758-0854.2010.01045.x

Duckworth, A. L., \& Seligman, M. E. P. (2005). Self-discipline outdoes IQ in predicting academic performance of adolescents. Psychological Science, 16(12), 939-944. https://doi.org/10.1111/j.1467-9280.2005.01641.x

Duckworth, A. L., \& Seligman, M. E. P. (2006). Self-discipline gives girls the edge: Gender in self-discipline, grades, and achievement test scores. Journal of Educational Psychology, 98(1), 198-208. https://doi.org/10.1037/0022-0663.98.1.198

Enriquez, V. G. (1977). Filipino psychology in the third word. Philippine Journal of Psychology, 10(1), 3-18.

Fenollar, P., Roman, S., \& Cuestas, P. J. (2007). University students' academic performance: An integrative conceptual framework and empirical analysis. British Journal of Educational Psychology, 77, 873-891. https://doi.org/10.1348/000709907X189118

Foster, I. R., Guo, Q., Xu, C. (n.d.). Is there an inverse relationship between study time and final exam scores? Evidence from principles of economics. Retrieved from https://www.aeaweb.org/conference/2015/retrieve.php?pdfid=827

Furlong, M. M., \& Christenson, S. L. (2008). Engaging students at school and with learning: A relevant construct for all students. Psychology in the Schools, 45(5), 365-368. https://doi.org/10.1002/pits.20302

Furrer, C., \& Skinner, Z. (2003). Sense of relatedness as a factor in children's academic engagement and performance. Journal of Education Psychology, 95(1), 148-162. https://doi.org/10.1037/0022-0663.95.1.148

Gable, S. S., \& Haidt, J. (2005). What (and Why) is positive psychology? Review of General Psychology, 9(2), 103-110. https://doi.org/10.1037/1089-2680.9.2.103

Hills, P., \& Argyle, M. (2002). The Oxford Happiness Questionnaire: A compact scale for the measurement of psychological well-being. Personality and Individual Differences, 33, 1073-1082. https://doi.org/10.1016/S0191-8869(01)00213-6

Jennings, G. (2003). An exploration of meaningful participation and caring relationships as contexts for school engagement. The California School of Psychologist, 8, 43-52. https://doi.org/10.1007/BF03340895

Jimerson, S. R., Campos, E., \& Greif, J. L. (2003). Toward and understanding of definitions and measures of school engagement and related terms. The California School of Psychologist, 8, 7-27. https://doi.org/10.1007/BF03340893

Kalmijin, W. (2013). From discrete 1 to 10 towards continuous 0 to 10: The continuum approach to estimating the distinction of happiness in a nation. Social Indicator Research, 110, 549-557.

https://doi.org/10.1007/s11205-011-9943-1

Layard, R. (2003). Happiness: Has social science a clue? Retrieved from http://eprints.lse.ac.uk

Lievens, F., Coetsier, P., De Fruyt, F., \& De Maeseneer, T. (2002). Medical students' personality characteristics and academic performance: A five-factor model perspective. Medical Education, 36, 1050-1056. https://doi.org/10.1046/j.1365-2923.2002.01328.x

Macan, H. T., Shahani, C., Dipboye, R. L., \& Phillips, A. P. (1990). College students' time management: Correlations with academic performance and stress. Journal of Educational Psychology, 82(4), 760-768. https://doi.org/10.1037/0022-0663.82.4.760 
Lumontod, R. Z., III.

Naseem, Z., \& Khalid, R. (2010). Positive thinking in coping with stress and health outcomes: Literature Review. Journal of Research and Reflections in Education, 4(1), 42-61.

Omidi, A., Akbari, H., \& Mahdian, M. (2011, December). Association of happiness, perceived stress and academic achievement in Kashan University of Medical Sciences students. Paper presented at the International Conference on Medical, Biological and Pharmaceutical Sciences, Pattaya.

Ott, J. C. (2011). Government and happiness in 130 nations: Good governance fosters higher level and more equality of happiness. Social Indicator Research, 102, 3-22. https://doi.org/10.1007/s11205-010-9719-z

Perez, J. A. (2012). Gender difference in Psychological well-being among Filipino college student samples. International Journal of Humanities and Social Science, 2(13), 84-93.

Platsidou, M. (2013). Trait emotional intelligence predicts happiness, but how? An empirical study in adolescents and young adults. International Journal of Well-being, 3(2), 197-209.

Pomerantz, E. M., Altermatt, E. R., \& Saxon, J. L. (2002). Making the grade but feeling distressed: Gender differences in academic performance and internal distress. Journal of Educational Psychology, 94(2), 396-404. https://doi.org/10.1037/0022-0663.94.2.396

Pordanjani, R. T., Yahyanezhad, F., \& Moharer, A. (2014). Self-efficacy, academic achievement and happiness. International Journal of Education and Applied Sciences, 1(4), 181-188.

Primasari, A., \& Yuniarti, K. W. (2012). What make teenagers happy? An exploratory study using indigenous psychology approach. International Journal of Research Studies in Psychology, 1(2), 53-61. https://doi.org/10.5861/ijrsp.2012.v1i2.80

Rasul, S., \& Bukhsh, Q. (2011). A study of factors affecting students' performance in examination at university level. Procedia Social and Behavioral Sciences, 15, 2042-2047. https://doi.org/10.1016/j.sbspro.2011.04.050

Rode, J. C., Day, M., Mooney, C. H., Near, J. P., Baldwin, T. T., Bommer, W. H., \& Rubin, R. S. (2005). Life satisfaction and student performance. Academy of Management Learning \& Education, 4(4), 421-433. https://doi.org/10.5465/amle.2005.19086784

Sheard, M. (2009). Hardiness commitment, gender, and age differentiate university academic performance. British Journal of Educational Psychology, 79, 189-204. https://doi.org/10.1348/000709908X304406

Shelef, A., Zdaka, C., \& Barak, Y. (2015). Happiness amongst Israel Defense Force (IDF) mental health officers (MHO's). Disaster and Military Medicine, 1(7). https://doi.org/10.1186/2054-314X-1-7

Snoep, L. (2008). Religiousness and happiness in three nations: A research note. Journal of Happiness Studies, 9 , 207-211. https://doi.org/10.1007/s10902-007-9045-6

Steptoe, A., Dockray, S., \& Wardle, J. (2009). Positive affect and psychological processes relevant to health. Journal of Personality, 77(6), 1747-1776. https://doi.org/10.1111/j.1467-6494.2009.00599.x

Sue, D. L. (2009). The effect of scrambling test questions on student performance in a small class setting. Journal for Economic Educators, 9(1), 32-41.

Tabbodi, M., Rahgozar, H., Abadi, M. M. (2015). The relationship between happiness and academic achievements. European Online Journal of Natural and Social Sciences, 4(1), 241-246.

Telzer, E. H., \& Fuligni, A. J. (2009). A longitudinal daily diary study of family assistance and academic achievement among adolescents from Mexican, Chinese, and European backgrounds. Journal of Youth and Adolescence, 38, 560-571. https://doi.org/10.1007/s10964-008-9391-7

Tolentino, M. N., \& Dullas, A. R. (2015). Subjective well-being of Filipino farm children. International Journal of Research Studies in Psychology, 4(4), 47-60. https://doi.org/10.5861/ijrsp.2015.1265

Tuntiwarodom, L., \& Potipiti, T. (2008). Determinants of happiness and academic performance of economics students. Chulalongkorn Journal of Economics, 20(3), 183-200.

Ukpong, D. E., \& George, I. N. (2013). Length of study-time behaviour and academic achievement of social studies education students in the University of Uyo. International Education Studies, 6(3), 172-178. https://doi.org/10.5539/ies.v6n3p172

Veenhoven, R. (1997). Advances in understanding happiness. Revue Quebecoise de Psychologie, 18, $29-74$.

Veenhoven, R. (2006). How do we assess how happy we are? Tenets, implications and tenability of three theories. Paper presented at conference on New Directions in the Study of Happiness: United States and 
International Perspectives, University of Notre Dame, 2006. USA.

Veenhoven, R. (2008). Healthy happiness: Effects of happiness on physical health and the consequences for preventive health care. Journal of Happiness Studies, 9, 449-469. https://doi.org/10.1007/s10902-006-9042-1

Veenhoven, R. (2010). Greater happiness for a greater number is that possible and desirable? Journal of Happiness Studies, 11, 605-629. https://doi.org/10.1007/s10902-010-9204-z

Veenhoven, R. (2010). Life is getting better: Societal evolution and fit with human nature. Social Indicator Research, 97, 105-122. https://doi.org/10.1007/s11205-009-9556-0

Waters, L. (2011). A review of school-based positive psychology interventions. The Australian and Developmental Psychologist, 28(2), 75-90. https://doi.org/10.1375/aedp.28.2.75

Wenglinsky, H. (2002, February 13). How schools matter: The link between teacher classroom practices and student academic performance. Education Policy Analysis Archives, 10(12). Retrieved from https://epaa.asu.edu/ojs/article/viewFile/291/417

Xiao, J. J., Tang, C., \& Shim, S. (2009). Acting on happiness: Financial behaviour and life satisfaction of college students. Social Indicator Research, 92, 53-68. https://doi.org/10.1007/s11205-008-9288-6

Yiengprugsawan, V., Somboonsook, B., Seubsman, S., \& Sleigh, A. C. (2012). Happiness, mental health, and socio-demographic associations among a national cohort of Thai adults. Journal of Happiness Studies, 13, 1019-1029. https://doi.org/10.1007/s10902-011-9304-4

Yonezawa, S., Jones, M., \& Joselowsky, F. (2009). Youth engagement in high schools: Developing a multidimensional, critical approach to improving engagement for all students. Journal of Educational Change, 10, 191-209. https://doi.org/10.1007/s10833-009-9106-1

Zhang, H., \& Man Tsang, S. K. (2013). Relative income and marital happiness among urban Chinese women: The moderating role of personal commitment. Journal of Happiness Studies, 14, 1575-1584. https://doi.org/10.1007/s10902-012-9396-5

Zimmerman, B. J. (2000). Self-efficacy: An essential motive to learn. Contemporary Educational Psychology, 25, 82-91. https://doi.org/10.1006/ceps.1999.1016 
Lumontod, R. Z., III. 